OPEN ACCESS

Edited by:

David Andrew Luther, George Mason University,

United States

Reviewed by:

Phillip Cassey,

The University of Adelaide, Australia

Mark C. Mainwaring,

University of Montana, United States

*Correspondence:

Daniel S. Cooper

dcooper137@ucla.edu;

dan@cooperecological.com

Specialty section:

This article was submitted to Behavioral and Evolutionary Ecology,

a section of the journal

Frontiers in Ecology and Evolution

Received: 15 April 2020

Accepted: 10 July 2020

Published: 30 July 2020

Citation:

Cooper DS, Shultz AJ and

Blumstein DT (2020) Temporally

Separated Data Sets Reveal Similar

Traits of Birds Persisting in a

United States Megacity.

Front. Ecol. Evol. 8:251.

doi: 10.3389/fevo.2020.00251

\section{Temporally Separated Data Sets Reveal Similar Traits of Birds Persisting in a United States Megacity}

\author{
Daniel S. Cooper ${ }^{1,2 *}$, Allison J. Shultz ${ }^{2,3}$ and Daniel T. Blumstein ${ }^{1}$ \\ 1 Department of Ecology and Evolutionary Biology, University of California, Los Angeles, Los Angeles, CA, United States, \\ ${ }^{2}$ Ornithology Department, Natural History Museum of Los Angeles County, Los Angeles, CA, United States, ${ }^{3}$ Urban Nature \\ Research Center, Natural History Museum of Los Angeles County, Los Angeles, CA, United States
}

We present an analysis of life history and behavioral traits associated with urbanization for 52 breeding bird species on 173 survey blocks in the Los Angeles area of southern California, United States, across two time periods, 1995-1999 and 2012-2016. We used observational data from two community science efforts and an estimate of urban land cover in each block to develop an index of urban association, and then modeled the relationship between species occurrence and eight traits likely associated with urban tolerance. We found two traits to be significantly associated with urbanization in both eras: Structure-nesting (i.e., the tendency to build nests on human-built structures) was positively associated, and cavity-nesting (i.e., the tendency to build nests in natural tree cavities) was negatively associated. Our analysis provides a template for mining historical community science data, and for "retrofitting" contemporary data to gain insights into ecological trends over time, and illustrates the persistence of ecological traits of species associated with urban areas even as the makeup of these species communities may change.

Keywords: community science, citizen science, California, eBird, breeding bird atlas, life history traits, urban tolerance

\section{INTRODUCTION}

Understanding species' tolerance to urbanization will be key to conserving biotic diversity as global population increases and as more people move to cities (Vitousek et al., 1997; Marzluff, 2005). Various external factors, including mechanical noise, anthropogenic light, windows, and outdoor cats represent direct, urban-associated influences on bird distributions (reviewed by Marzluff, 2016). The process by which species invade and exploit novel environments has been referred to as "filtering" (Clergeau et al., 2001), and may be applied to those bird communities in or near urban areas, with certain species passing through the urban filter successfully or invading following urbanization, and others failing to do so (Lowry et al., 2013; Wingfield et al., 2015). Johnston (2001) recognized a gradient of tolerance from urban avoidance to synanthropy, or a dependence on the built environment, and this vocabulary has been expanded by numerous authors (e.g." "specialist" 
vs. "mutualist" species, from MacGregor-Fors and OrtegaAlvarez, 2011) to describe the affiliation between certain species and urban areas.

While urbanization tends to homogenize formerly complex ecological systems (McKinney, 2006; Devictor et al., 2007), certain specialist taxa may exploit urban sites preferentially, or may assemble into novel communities there (Møller et al., 2015), particularly where urban habitats are more structurally complex than those replaced, such as grassland or low scrub (e.g., Emlen, 1974; Gonzalez-Garcia et al., 2014). Certain types of food/prey and nesting sites may be superabundant in urban areas, owing to the presence of lush, landscaped vegetation, anthropogenic water and supplemental feeding (Chace and Walsh, 2006), though this availability may be offset by novel hazards such as feral cats (Loss et al., 2013). Thus, not all species that thrive in urban areas are drawn to hardscape or modified vegetation; some may simply maintain populations in habitat fragments within an otherwise urbanized landscape, for example marshdwelling birds occurring at small urban wetlands, along floodcontrol channels.

Efforts to identify traits that allow species (or individuals of the same species) to tolerate and even thrive with urbanization date to the early 1960s; more recently, the term "urban bird syndrome" has been coined to capture behavioral, physical, reproductive, and ecological traits (see Møller, 2014; Samia et al., 2015 for meta-analyses and summaries of prior findings). Urban birds tend to display behavioral boldness and "innovation propensity," which compels individuals to explore new habitats and become established in these areas (Atwell et al., 2012; Blumstein, 2014; see review by Sol et al., 2017). They have shorter flight initiation distances (FID) and exhibit heightened predator avoidance (Blumstein, 2006; Møller, 2010), heightened territoriality and aggression (Evans et al., 2010), and reduced vocalizations (Estes and Mannan, 2003). They also tend to have a broader elevational tolerance (Bonier et al., 2007) and a larger geographical range (Møller, 2009). Morphological variables have also been found to be associated with urbanization in birds, including body size (small size for raptors; Chace and Walsh, 2006), and wingspan (large wingspan for passerines; Croci et al., 2008). It is important to note that these studies include those that compared traits across multiple species, as well as those that investigated traits of individuals within the same species.

Diet studies have consistently found positive associations between urbanization and granivory, and negative associations between urbanization and insectivory, including for groundforaging insectivores (Kark et al., 2007; Croci et al., 2008; Evans et al., 2011; reviewed by Chace and Walsh, 2006). Habitat preference studies have found that urban passerines are disproportionately represented by forest species (Croci et al., 2008), and by species exhibiting a wide habitat breadth (Sol et al., 2014). Urban birds also tend to be non-migratory both globally (Sol et al., 2014) and regionally in Europe (Croci et al., 2008) and Israel (Kark et al., 2007).

Many breeding behaviors have also been associated with urbanization, and studies examining nesting phenology have found earlier nest initiation both for urban raptors (Boal and
Mannan, 1999; Kettel et al., 2018), and for species that visit (urban) feeders (O'Leary and Jones, 2006). Several authors have noted that urban areas would favor species that nest on humanmade structures tend (reviewed by Chace and Walsh, 2006), and would disadvantage those that use natural cavities (Blewett and Marzluff, 2005) as well as ground-nesting species (Evans et al., 2011; Sol et al., 2014). Comparisons of nest productivity, clutch size, nest site preference and food-provisioning (to young) among urban bird populations have yielded contradictory results, as noted by Chace and Walsh, (2006; see also Lowry et al., 2013; Marzluff et al., 2015). Likewise, there appears to be little difference in the cognitive abilities of urban vs. rural populations of the same species, as measured by problem-solving ability and relative brain size (e.g., Carrete and Tella, 2011; Sol et al., 2014).

But do these patterns persist through time, in that the same traits that connote success in urban areas do so year after year? Marzluff et al. (2001) recommended that tolerance to urbanization be re-assessed for species over time, because patterns of human activity are constantly changing, with cities adopting new architectural styles and landscaping palettes. A species' basic behavior also may change as populations become more tolerant to human disturbance; for example, they may become habituated to elevated noise and city lights (e.g., Slabbekoorn and den Boer-Visser, 2006; Francis et al., 2009). Conversely, for the most sensitive species, even slight increases in human disturbance may have lasting negative consequences (e.g., from recreational activity within natural open space areas, Pauli et al., 2016), leading to loss of biodiversity over time. Thus, behavioral plasticity, as well as tolerance, may also connote success in urban areas, where birds that readily alter their behaviors would thrive in cities, while those that cannot either decline and vanish, or they never colonize (West-Eberhard, 1989; Sol et al., 2013; Jokimäki et al., 2017). While studies of bird assemblages across gradients of urbanization ("space for time") date to the 1970s (Emlen, 1974; Beissinger and Osborne, 1982; Blair, 1996), those that investigate the same community over time are much less common (but see Aldrich and Coffin, 1980; Shultz et al., 2012), and we are not aware of any that explicitly investigate ecological traits associated with urbanization across two temporal eras.

The Los Angeles metropolitan area of southern California, United States (which includes the city of Los Angeles), is an ideal place to study urban tolerance and persistence in bird species, due to its long history of ornithological investigation (e.g., Grinnell, 1898; Swarth, 1900), its high human population, the large areas of open space present around its borders and even within the urban core, and its large and active birding and citizen-scientist community (Higgins et al., 2019; Li et al., 2019). Its diverse avifauna is also in constant flux in terms of species abundance and distribution (Allen et al., 2016; Garrett, 2018); some local species have long been present and common in Los Angeles' urban environment, such as House Finches (Haemorhous mexicanus), while others, such as Dark-eyed Juncos (Junco hyemalis), appear to be in a more recent process of shifting from wildland-favoring and somewhat migratory, to ubiquitous year-round residents (Yeh, 2004). 
We developed two separate databases separated by nearly 20 years, "retrofitting" modern eBird data" to an older dataset from the breeding bird atlas effort in the 1990s (Allen et al., 2016) to understand: (a) which ecological, behavioral and morphological traits of nesting birds are associated with urban landscapes, and (b) whether this has changed in the past 15-20 years. We calculated an "urban index" for each species based on its detections within each of 173 survey blocks, correlated with urban cover data. This index served as a measure of association with urbanization, and we used this value as a response variable in multiple models incorporating eight life history and behavioral traits, body mass, nest height (lowest), ground foraging, migratory status, natural cavity nesting, artificial structure nesting, habitat breadth, and diet breadth. We fitted this model for both the early era and late era datasets, and examined whether the same traits were associated with our urban index during each era.

By examining a range of traits that may account for shifts in range across the region, we aimed to gain insights into possible mechanisms behind species' increases and decreases in urban areas, and potentially resolve some of the previously contradictory findings about species traits associated with urban areas. Our findings may have conservation implications, because the presence of typically urban-avoiding species can be seen as an indication of ecosystem health, while conversely, the spread and prevalence of urban-tolerant species may indicate an ecosystem that has been disrupted, or one that has changed from its former, more natural state. By using two different datasets, separated by up to 20 years, we test the durability of these findings to explain patterns of urban association in birds.

\section{MATERIALS AND METHODS}

\section{Study Area}

We consider the "Los Angeles area" to be the entire southern half of the ca. $10,000 \mathrm{~km}^{2}$ expanse of Los Angeles County, which includes all or portions of more than 80 incorporated cities. The study area includes all coastal-draining land in the county below ca. $1,000 \mathrm{~m}$ above sea level, from the Santa Monica Mountains and San Fernando Valley east through the San Gabriel Valley to the San Bernardino County line, south to the Pacific Ocean, including the Puente Hills and Palos Verdes Peninsula, while excluding offshore islands (Figure 1). The native habitats of the Los Angeles area, now largely limited to its perimeter (but penetrating the central urban core via the Santa Monica Mountains), include a diverse mix of evergreen chaparral (dominated by large shrub species in the Anacardiaceae, Rosaceae, and Rhamnaceae families), low, summer-deciduous scrub (including coastal sage scrub, featuring sages Salvia spp.), patches of evergreen woodland (dominated by coast live oak Quercus agrifolia), plus numerous microhabitats such as riparian woodland and scrub, alluvial fan scrub, and both seasonal and permanent wetlands (e.g., Schoenherr, 1992; Stein et al., 2007). Historically, the floor of the Los Angeles Basin

${ }^{1}$ www.ebird.org was dominated by low scrub and prairie-like grassland, now essentially replaced by residential and commercial development.

We excluded the Santa Clara River valley/Santa Clarita area north of the study area, because it is separated from the main Los Angeles Basin by a high pass (Newhall Pass) and features a slightly different avifauna typical of more interior locations in the state. While the study area includes many microclimates (e.g., the coastal areas are cooler during the summer than the interior areas), no major natural impediments to bird dispersal exist.

\section{Urban Cover}

Because urban areas may be defined at multiple scales, there is neither global consensus on what constitutes "urban habitat," nor on how best to describe habitats modified by humans yet still retaining important natural elements (Croci et al., 2008; MacGregor-Fors, 2010; Evans et al., 2011; Beninde et al., 2015; but see White et al., 2005; Li et al., 2019). As a measurement of the degree of urbanization in our study area, we calculated urban cover using the "Urban/Built-Up" category in the statewide vegetation mapping dataset "CALVEG," which was created between 2002 and 2003 (CALVEG, 2009; 1 ha mapping units). CALVEG was found to be the most popular California vegetation layer in a recent online survey (Center for Geographical Studies, 2015), and is frequently used in species distribution studies at the scale of ours (e.g., Santos et al., 2017; City of Los Angeles, 2018). This catch-all Urban/Built-Up coverage includes humanmade structures such as buildings and roads, but also manicured parks, golf courses and cemeteries, which, in the Los Angeles area, tend to lack natural, native vegetation (as of 2003). Our urban cover designation includes the habitat now commonly referred to as "urban forest" (Wood and Esaian, 2020), as distinct from natural open space, which may include native forest types, as well as many other natural habitat types. We overlaid the survey block boundaries onto the urban/built-up coverage using QGIS (QGIS Development Team,, 2016), and calculated the amount of urban cover in each of the 173 survey blocks (for a description of survey blocks see Breeding Bird Data).

We used the same urban cover values when modeling both the early and late era datasets (our CALVEG coverage was developed in the years between the two eras), because separate land use data at a suitable scale do not exist for each era. We recognize that both housing density increases and localized development continues to occur across the study area (ca. 3\% increase in the county's population between 2000 and 2010; Los Angeles Almanac,, 2019) and that absolute tree cover increased dramatically over the past century as the urban forest replaced a landscape that had been dominated by arid scrub and grassland (Gillespie et al., 2011). However, relative urbanization within the study area have remained constant across our survey blocks, in that the most highly urbanized blocks were highly urban in both the early and late era used here, and the least urbanized blocks in the 1990s are still the least urbanized today, such as those in the Santa Monica Mountains (see maps in Lee et al., 2017).

\section{Species Selection}

Of the 228 bird species in the Los Angeles County Breeding Bird Atlas, we eliminated 176 species of these due to various 


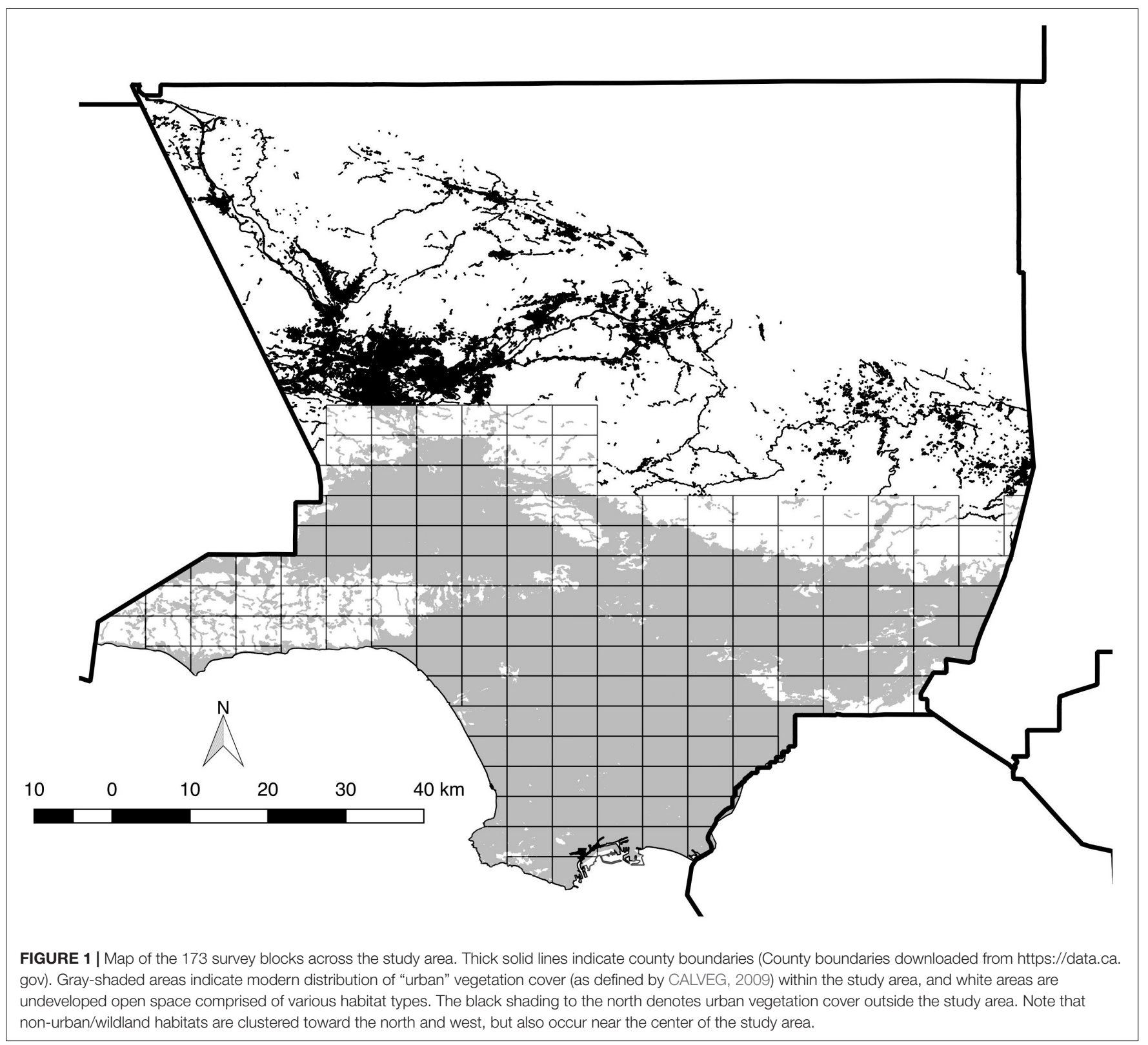

factors that would interfere with an analysis of urban association, including very low regional population size, specific microhabitat requirements (which may not be present throughout the study area), and tendency to wander during the breeding season. We first excluded species that occur only in montane/desert areas outside the Los Angeles area, and marine species found along the immediate coast or on offshore islands. We then excluded species due to regional rarity (i.e., those detected on $<30$ survey blocks of the study area during the breeding season in both the early and late eras), since we were interested in birds that could potentially occur anywhere in the study area, and that were not in low numbers due to some other factor. We then eliminated those associated with specific and localized habitats, such as wetlands, riparian, specific types of scrub, and those known to be grasslandobligate species, since these habitats were found narrowly and patchily in the study area, and likely contribute more to the distribution of species than degree of urbanization. We further eliminated nocturnal species, as well as aerial foragers such as swallows (Hirundinidae) and those species that travel widely, often across multiple survey blocks, during daily foraging activity (e.g., Psittacidae), to avoid counting the same individual birds in multiple blocks and assuming they were breeding in these blocks. Finally, we eliminated species that tend to have such protracted migratory periods that it is difficult to tell when they are actually on breeding territories or simply moving through, such as Blackheaded Grosbeaks (Pheucticus melanocephalus), which frequently wander through the region for much of the late spring/summer (see Unitt, 2004).

Our final list of 52 species thus includes those that were: (a) widespread enough to be found (or expected) across the study 
area, (b) likely nesting where they are detected in spring/early summer, and c) habitat generalists, occurring in woodland and shrubby vegetation that represents the dominant habitat across the Los Angeles area, and which is simulated by ornamental plantings such as hedges and street trees. We included several introduced taxa that we knew to be tied to urbanized/modified habitats, such as Scaly-breasted Munia (Lonchura punctata). Our final focal species list thus represents a mix of resident and migratory status, size classes (e.g., raptors to hummingbirds), and a diversity of morphological and ecological attributes, with each species having the potential to occur as breeding species in all regions of the study area, and whose presence on a survey block during the breeding season would strongly suggest local nesting on that block.

\section{Breeding Bird Data BBA (Early Era Dataset)}

From 1995 to 1999, the Los Angeles County Breeding Bird Atlas was organized around 414 blocks based on USGS topo quads (each roughly $5.8 \mathrm{~km} \mathrm{E-W} \times 4.6 \mathrm{~km} \mathrm{~N}-\mathrm{S}$, or 2,668 hectares; some blocks were larger or smaller along county lines). Each atlas volunteer was assigned one or more blocks and given detailed instructions on how to confirm nesting for as many species as possible within that block, over the span of 5 years. Species were assigned three levels of breeding status for each block (i.e., "confirmed," "probable," or "possible" breeding) based on standardized breeding indicators used during the atlas effort (e.g., singing male represented "possible" breeding, carrying nesting material and feeding young represented "confirmed" breeding, etc.). All data were pooled into an overall "highest breeding status" value, by block, and no specific effort data were collected during the atlas project (i.e., how much observational time was spent within each block). In all, 22,840 records were amassed for 228 species (not all of them confirmed as breeding) by 98 observers searching their blocks. An additional 5,320 "casual observations" by 218 observers were submitted to the atlas project during the atlas period, for a total of 28,935 breeding records analyzed and vetted by staff of the Natural History Museum of Los Angeles County (Allen et al., 2016). We analyzed only the 173 atlas blocks that fell within our coastal lowland study area (see section "Study Area").

\section{EBird (Late Era Dataset)}

Data from eBird ${ }^{2}$ are collected in a completely different way than the BBA data, with sightings submitted opportunistically by birders from either a specific, georeferenced location, or from somewhere within a larger "hotspot" (typically a park or a trail). EBird data prior to 2,000 are relatively sparse compared to more recent years (hence our incorporation of breeding bird atlas data), and the platform continues to gain in global popularity (as of December 2019, eBird "checklists" - observations of one or more species by a registered eBird user for a particular location, date and time period - were being submitted at the rate of ca. 50,000 per year for Los Angeles County, one of the most actively birded regions of the world). After obtaining all Los Angeles

${ }^{2}$ www.eBird.org
County eBird records for 2012-2016 (1.36 million records), We used the software R (version 3.4.1., R Foundation for Statistical Computing, Wien, Austria) to create a database of sightings that fit our criteria for analysis. Some "coarsening" was necessary to directly compare the breeding status of species from the BBA to that derived from eBird data, as BBA data were reported at the level of atlas block, while eBird data is reported by point data. We assigned each eBird record to a particular atlas block using a spatial join function in QGIS (QGIS Development Team,, 2016).

To further refine the eBird data, records of each focal species were filtered by "safe date," a range of dates for which the presence of that species within a set of dates would be indicative of at least "possible" breeding in the County, as determined during the atlas effort. In certain cases, we used the reported dates of local breeding in lieu of safe dates (e.g., for "breeds late March to early July," we used March 15 to July 15) if they were not provided by Allen and Garrett (1995) for the atlas. Records outside these dates were discarded. Because observations of breeding behavior are not frequently reported in eBird checklists, we could rarely distinguish between "probable" and "confirmed" breeding. Therefore, we considered each species "probable/confirmed" for a given survey block if more than two individuals were observed at a single location (i.e., eBird Hotspot or personal location) during the safe (or designated breeding) dates for any year during the 2012-2016 period. We assigned species as being a "possible" breeder in the block if just one individual was detected with the safe dates, and noted a species as "not breeding" if it was not recorded at all within safe dates.

Because we had no observer effort associated with the BBA data, we did not calculate observer effort for the late era (eBird) data, but worked under the assumption that the most-visited sites in the late 1990s were the same (or were in the same survey blocks) as those from 2012-2016. Likewise, we maintained a conservative approach in data analyses and did not attempt to calculate species abundance within blocks, nor number of years when observed, but simply counted a bird as achieving the highest breeding category during a particular span of years (i.e., replicating what was done for the BBA project). As reviewed by Horns et al. (2018) eBird data, even while opportunistically collected, produces similar results to other forms of observational data collection across large geographical scales, so we felt comfortable comparing the two datasets (BBA and eBird).

\section{Breeding Level and Urban Index}

We entered three "breeding levels" for each species, for each survey block, during each era $(0=$ no record, $1=$ possible breeding or 2 = probable/confirmed breeding). We then calculated an "urban index" for each species during each era, which was the correlation coefficient between that species' breeding level within each block (0-2) and the percent urban cover value within that block, using a Spearman's rank test with the rcorr function in R using the Hmisc package (Harrell, 2004). A positive urban index would indicate a positive association between a species and urban cover, while a negative urban index would indicate a negative association with urban cover; an urban index near zero would indicate no association with urban cover. The urban index served as our response variable, 
and formed the basis for our trait analysis, below (see also Supplementary Table S1).

Because the survey blocks used are arranged in a grid, and urban development in the Los Angeles area includes large, continuous areas of urbanization (as well as large blocks of open space), urban cover was necessarily autocorrelated (Moran's I observed: 0.019 , expected: $-0.006, S D=0.009, P=0.010)$. We sought to reduce any error introduced via spatial autocorrelation by using a single urban index value for each species, which was not spatially explicit, but reflected the association between bird distribution and urban cover.

We first tested for a phylogenetic signal in the urban index values for both the early/BBA values and the late/eBird values, using models that employed three different modes of evolution: Brownian motion, Pagel's lambda, Ornstein-Uhlenbeck, as well as a non-phylogenetic model (see Münkemüller et al., 2012). We used the ape (Paradis et al., 2004), geiger (Pennell et al., 2014), and picante (Kembel et al., 2010) packages in R, and used the phylosignal function to analyze the focal species' urban index relative to their corresponding positions on the phylogenetic tree described above. We first tested a Brownian motion, or random-walk model, using a Blomberg's $K$ test (Blomberg et al., 2003), which compares the variance of phylogenetic independent contrasts to what we would expect under a Brownian motion (BM) model. Here, $K=1$ means that relatives resemble one another as much as we should expect under BM; $K<1$ means that there is less "phylogenetic signal" than expected under BM, while $K>1$ means that there is more. We then analyzed the urban index and tree data using Pagel's lambda (Pagel, 1999). Here, if our estimated lambda $=0$, then the traits are inferred to have no phylogenetic signal. Lambda $=1$ corresponds to a Brownian motion model; $0<$ lambda $<1$ is intermediate. Finally, we used a model which employed the Ornstein-Uhlenbeck (OU) mode of evolution which incorporates stabilizing selection wherein the trait is drawn toward a fitness optimum, or long-term mean, rather than being completely random and directionless (Martins, 1994). To test for no phylogenetic signal, we also used a "nosignal" generalized least squares model where lambda was set to 0 .

\section{Trait Analysis}

We identified eight life history and behavioral traits likely associated with urban tolerance based on those identified in previous studies (e.g., Møller, 2014; Samia et al., 2015): body mass, nest height (lowest), ground foraging, migratory status, natural cavity nesting, artificial structure nesting, habitat breadth, and diet breadth (Table 1). We were limited in which variables we could use for subsequent modeling by data gaps (e.g., flight initiation distance has been calculated for fewer than half the focal species; D.T. Blumstein, unpubl. data). To account for phylogenetic relatedness among species in our analyses, we used an avian phylogeny from Bird Tree (Jetz et al., 2012, 2014). With our list of 53 species, we used the phylogeny subset tool (in Bird Tree) to create 1,000 trees built with a Hackett et al. (2008) backbone. For use in subsequent analyses, we created a majorityrule consensus tree, collapsing nodes that did not show up in at least $50 \%$ of the 1,000 trees.
TABLE 1 | Functional traits considered for this analysis.

\begin{tabular}{|c|c|c|}
\hline Trait & Description & Source \\
\hline Adult body mass & $\begin{array}{l}\text { Total weight (grams; of male if } \\
\text { different) }\end{array}$ & Dunning, 2007 \\
\hline Lowest nest height & $\begin{array}{l}\text { Meters; lowest average nest } \\
\text { height }\end{array}$ & $\begin{array}{l}\text { Ehrlich et al., 1988; } \\
\text { BNA }\end{array}$ \\
\hline $\begin{array}{l}\text { Forage ground only } \\
\text { (during breeding } \\
\text { season) }\end{array}$ & $\begin{array}{l}\text { Categorical }(2 ; 0 / 1) \text {; forages } \\
\text { exclusively or mainly on the } \\
\text { ground }\end{array}$ & Wilman et al., 2014 \\
\hline Migratory status & $\begin{array}{l}\text { Categorical }(2 ; 0 / 1) \text {; } \\
\text { non-migratory, partially/fully } \\
\text { migratory }\end{array}$ & eBird \\
\hline Cavity nest & $\begin{array}{l}\text { Categorical }(2 ; 0 / 1) \text {; frequently } \\
\text { uses tree cavities for nesting. }\end{array}$ & Allen et al., 2016 \\
\hline Structure nest & $\begin{array}{l}\text { Categorical ( } 2 ; 0 / 1) \text {; frequently } \\
\text { uses human-made structures for } \\
\text { nesting (excluding bird boxes) }\end{array}$ & Allen et al., 2016 \\
\hline Habitat breadth & Level (3; 1-3) & $\begin{array}{l}\text { Garrett and Dunn, } \\
1981\end{array}$ \\
\hline Diet breadth & Level $(6 ; 1-6)$ & $\begin{array}{l}\text { Sekerciglou, unpubl. } \\
\text { data }\end{array}$ \\
\hline
\end{tabular}

BNA, Birds of North America (various authors, https://birdsna.org/).

We then tested the association between these traits and each species' affiliation for urban cover using the urban index as the dependent variable (using both the "early" and "late" values in separate tests), and the eight traits as independent variables. In separate tests (early and late) we ran three phylogenetic generalized least squares (PGLS) tests and one non-phylogenetic GLS tests using each, and compared AIC values of each to select the model that best explained variation in the data.

We used the gls function in the nlme package in $\mathrm{R}$ (Pinheiro et al., 2019), and incorporated a Brownian motion mode of evolution using the corBrownian function in the phytools package in $\mathrm{R}$ (Revell, 2012), along with our phylogenetic tree data. We conducted a second PGLS test using the Ornstein-Uhlenbeck (OU) mode of evolution using the corMartins function in the sde package in $\mathrm{R}$ (Iacus, 2016). We conducted a third PGLS test using Pagel's lambda test with the corPagel function also in the sde package. We fitted a non-phylogenetic least squares model to compare with the PGLS tests. For all analyses, best fit parameters of the phylogenetic model were estimated with maximum likelihood. Lastly, we checked residuals for normality using QQ tests, and selected the analysis with the lowest AIC values as the best model.

\section{RESULTS}

\section{Urban Index}

Nearly all focal species (48 of 52 species) showed an increase (i.e., toward positive) in urban index over time (Supplementary Table S1), and while we cannot directly compare urban indices between the two eras due to the different methodologies used in data collection, some of these species shifted from a negative or neutral urban index to a positive one, suggesting they may now be preferring urban habitats - or, at least, natural habitats near 
urban areas - over blocks with a greater percentage of natural vegetation. These "shifters" include representatives from diverse families, including Cooper's Hawks (Accipiter cooperii) $(-0.34$ to 0.15), Allen's Hummingbirds (Selasphorus sasin) (0.10 to 0.24), and Hooded Orioles (Icterus cucullatus) $(-0.15$ to 0.15$)$. At the other end of the spectrum, those with the largest negative residual values include California Quail (Callipepla californica), Wrentits (Chamaea fasciata) and Spotted Towhees (Pipilo maculatus). By contrast, very few species shifted from positive (i.e., more urbanassociated) to negative (Supplementary Table S1). We plot species' representation on survey blocks (Figure 2A) as well as the urban indices for each species (Figure 2B), showing that both values are highly correlated across eras $\left(r_{p}=0.80, P<0.001\right.$ for number of blocks where suspected/confirmed breeding; $r_{p}=0.90$, $P<0.001$ for urban index).

We found no indication of a phylogenetic signal in the urban index value using three phylogenetic models (Brownian motion, $\mathrm{O}-\mathrm{U}$, and Pagel's lambda), with the non-phylogenetic model returning the lowest AIC value (Table 2).

\section{Trait Analysis}

We found that two traits (cavity-nesting and structure-nesting) were significantly associated $(p<0.05)$ with urban index values using both the early and late eras in most models examined. We found migratory status was significantly associated with urbanization in the early era dataset (but not in the late era dataset). Cavity-nesting and migratory status were negatively associated with the urban index (that is, cavity-nesting and migratory birds were more associated with natural habitat), while structure-nesting was positively associated with the urban index. While the AIC score of the non-phylogenetically informed GLS was not sufficiently different from the OU and Pagel's lambda models (Table 3), these models had nearly identical associations with urban index in both the early and late era datasets. We summarize the results of the best model (non-phylogenetically informed GLS) in Table 4.

Non-significant negative associations were detected in several models (including the best/non-phylogenetically informed GLS model) for body mass, ground-foraging, migratory status and habitat breadth, and non-significant positive associations with nest height and diet breadth. While they did not rise to the level of significance (i.e., $P>0.05$ ), they were consistent in their direction across temporal eras.

\section{DISCUSSION}

Our study is one of very few to analyze the persistence of avian traits using both historical and current community-science data, and adds to an ample literature on why some birds thrive in urban areas and others avoid them. Our results suggest that nest site choice and migratory status may confer either an
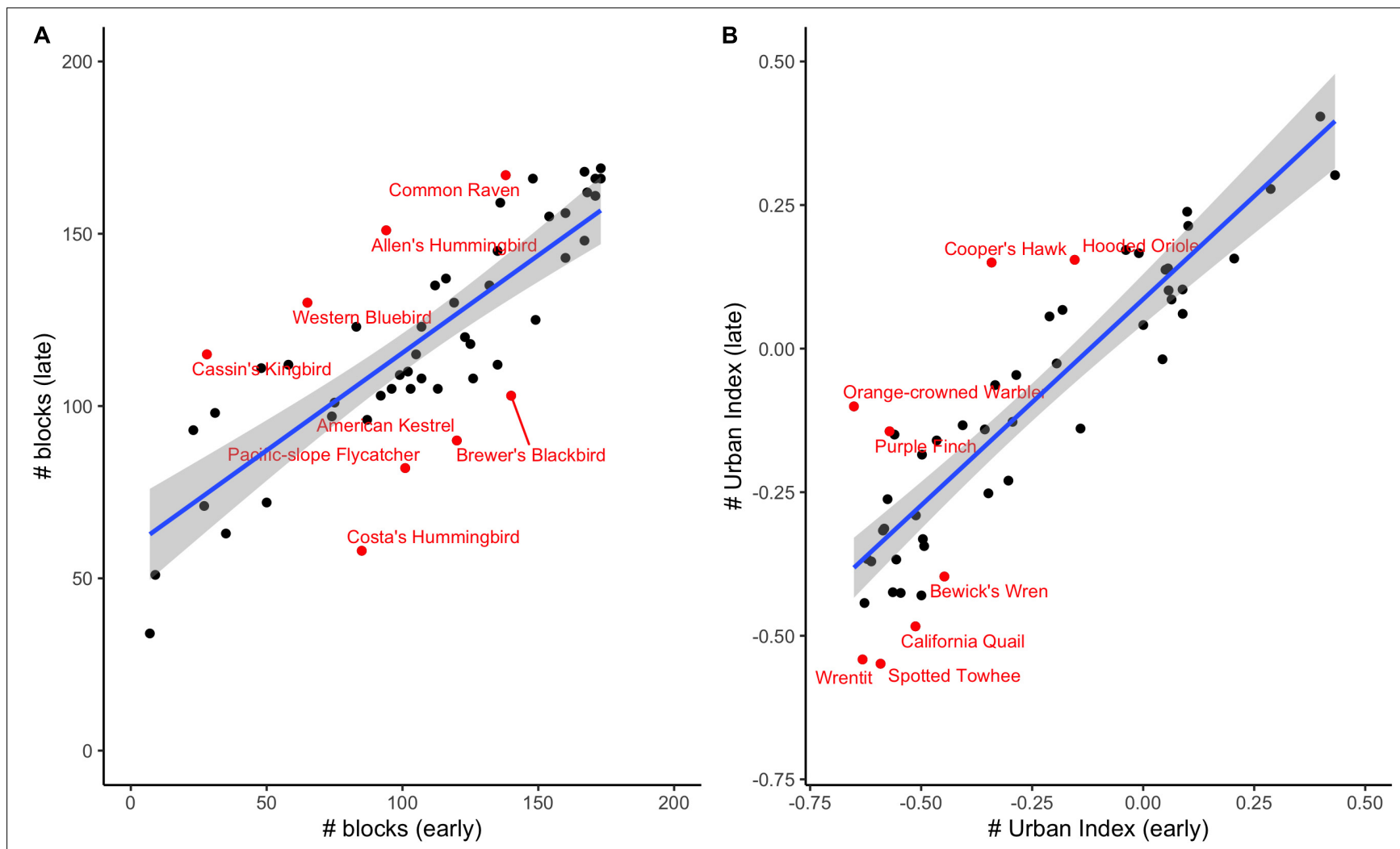

FIGURE 2 | (A) A comparison of species occurrence in early and late eras by number of blocks where suspected/confirmed breeding. (B) A comparison of urban index values between the early and late eras. We have labeled the species with the largest residuals from the blue best-fit line. 
TABLE 2 | Comparison of three phylogenetically informed Generalized Least Squares (PGLS) models (Brownian, OU, Pagel's lambda) and one non-phylogenetically informed model (GLS).

\begin{tabular}{|c|c|c|}
\hline Model & Test statistic & $\mathrm{AlCc}$ \\
\hline \multicolumn{3}{|c|}{ Early era (BBA data) } \\
\hline Brownian & $K=0.223 ; P=0.239$ Alpha: 2.718 & 66.727 \\
\hline OU & Sigma squared: 0.544 & 34.391 \\
\hline Pagel's lambda & $L<0.001 ; P=1$ & 34.406 \\
\hline Non-phy. & Sigma squared: 0.001 & 32.151 \\
\hline \multicolumn{3}{|c|}{ Late era (eBird data) } \\
\hline Brownian & $K=0.189 ; P=0.452$ Alpha: 2.718 & 38.826 \\
\hline OU & Sigma squared: 0.361 & 13.118 \\
\hline Pagel's lambda & $L<0.001 ; P=1$ & 13.099 \\
\hline Non-phy. & Sigma squared: 0.001 & 10.844 \\
\hline \multicolumn{3}{|c|}{$\begin{array}{l}\text { Here we use urban index scores only as our response variable (i.e., no } \\
\text { behavioral or life history traits). The lowest AlCc score was found using the } \\
\text { non-phylogenetic model. }\end{array}$} \\
\hline \multicolumn{3}{|c|}{$\begin{array}{l}\text { TABLE } 3 \text { | Comparison of AIC scores of best model (non-phylogenetic GLS) using } \\
\text { urban index as the response variable and eight behavioral and life history traits as } \\
\text { the predictor variables. }\end{array}$} \\
\hline Model & Early era (BBA) & Late era (eBird) \\
\hline Brownian & 93.724 & 71.685 \\
\hline OU & 66.988 & 51.695 \\
\hline Pagel's lambda & 68.619 & 51.522 \\
\hline Non-phylogenetic & 66.979 & 49.695 \\
\hline
\end{tabular}

Full model results are available in the Supplementary Materials.

TABLE 4 | Results from the best model in both time eras (non-phylogenetic GLS) fitted to explain variation in the urban index values based on eight life history and behavioral traits (includes standard error and $P$-value).

\begin{tabular}{lcc}
\hline & Early era (BBA) & Late era (eBird) \\
\hline Intercept & $-0.240 \pm 0.161 ; P=0.142$ & $-0.038 \pm 0.131 ; P=0.773$ \\
Trait & $-0.041 \pm 0.041 ; P=0.330$ & $-0.031 \pm 0.034 ; P=0.372$ \\
Log(adult mass) & $0.009 \pm 0.007 ; P=0.238$ & $0.010 \pm 0.006 ; P=0.093$ \\
Nest height & $-0.070 \pm 0.120 ; P=0.563$ & $-0.071 \pm 0.098 ; P=0.471$ \\
Ground-foraging & $-\mathbf{0 . 2 0 1} \pm \mathbf{0 . 0 9 9 ;} \boldsymbol{P}=\mathbf{0 . 0 4 7 *}$ & $-0.131 \pm 0.081 ; P=0.105$ \\
Migratory status & $-\mathbf{0 . 2 0 8} \pm \mathbf{0 . 0 9 8 ;} \boldsymbol{P}=\mathbf{0 . 0 4 0 *}$ & $-\mathbf{0 . 2 0 6} \pm \mathbf{0 . 0 8 0} \boldsymbol{P}=\mathbf{0 . 0 1 4}$ \\
Cavity-nesting & $\mathbf{0 . 2 6 4} \pm \mathbf{0 . 0 9 2 ;} \boldsymbol{P}=\mathbf{0 . 0 0 6 *}$ & $\mathbf{0 . 1 9 1} \pm \mathbf{0 . 0 7 5 ;} \boldsymbol{P}=\mathbf{0 . 0 1 4}$ \\
Structure-nesting & $0.060 \pm 0.038 ; P=0.135$ & $0.032 \pm 0.031 ; P=0.301$ \\
Diet breadth & $-0.049 \pm 0.052 ; P=0.355$ & $-0.051 \pm 0.043 ; P=0.238$ \\
Habitat breadth & 0.295 & 0.235 \\
Residual standard & & \\
error & &
\end{tabular}

Please refer to Supplementary Materials for full model results. Asterisk and bold font denote $P<0.05$.

advantage (for artificial structure nesters and sedentary species) or a disadvantage (for cavity nesters and for migratory species) within urban areas, that these patterns may persist over time (even if the makeup of the species community changes) using two different data collection methodologies (i.e., a BBA dataset vs. an eBird dataset). The durability of these traits through time was suggested by Shultz et al. (2012), who found levels of functional diversity maintained in an urban bird community over a century, despite changes in community composition as the area urbanized (see also Hagen et al., 2017). Indeed, the lack of a strong phylogenetic signal in patterns we documented (in either era) suggests that urban tolerance is not restricted to a few related species, but rather occurs across unrelated taxa, as observed in both birds and other taxonomic groups (Martin and Bonier, 2018; Merckx et al., 2018; Santini et al., 2019).

The significant negative association between cavity nesting and urban index may be a result of urban tree species in urban Los Angeles having been selected for their longevity, rapid growth, and resistance to boring pests (Gutzat and Dormann, 2018; Frank et al., 2019), and the tendency for large urban trees, especially those with dead limbs ("snags") to be removed in residential areas due to safety concerns (falling branches injuring people). It may be that more successful urban nesters would be those species that are able to utilize a variety of built structures (as well as natural cavities), including eaves of buildings, parking garages, and overpasses, with this flexibility allowing them to switch between substrates when one is not available. It is also possible that aggressive (urban-tolerant) cavity nesters such as European Starlings (Sturnus vulgaris) and/or parrots may be displacing natural cavity nesters within urban areas, though direct evidence of this is lacking (Koch et al., 2012; Diamond and Ross, 2019). Still, avian diversity in urban areas could be enhanced by provisioning artificial nesting structures, and maintaining natural nesting sites such as dead trees (see Tomasevic and Marzluff, 2017), as well as by retaining patches of natural habitat of various sizes within the urban matrix (Silva et al., 2015) and by planting a diversity of trees and shrubs as part of landscaping (Wood and Esaian, 2020).

We found no significant correlations between urban index and body mass, ground foraging, or either diet or habitat breadth, all of which have been found to be associated with urban in prior studies (e.g., Chace and Walsh, 2006; Evans et al., 2011). It could be that the large scale of the atlas blocks (ca. 2,668 ha) encompassed a variety of habitat types and variety of urban conditions (which we did not analyze here), so a finer-level analysis (e.g., eBird point data) might detect more significant associations (see Croci et al., 2008; Ferenc et al., 2014 for discussions of scale). While not statistically significant, the consistent positive associations found between urban index and nest height may indeed be "real," as so many structure-nesting birds nest atop towers, buildings, and other tall features of the urban environment, which are less prevalent in wildland habitats and which would become more common over time in urban areas as infill hardscape development displaces vegetation (e.g., Lee et al., 2017). Likewise, the consistent negative association with migratory status across several models used, while (weakly) significant only during the early era, may become stronger with additional (migratory) species included in a future analysis (including data from multiple cities), or with finer-grain migration data (our binary "migratory status" trait does reflect the range of long- and short-distance and partial migrants).

We also note that certain species are clearly modifying their tolerance to local urbanization as they increase in distribution within the study area, which may lead to concurrent changes 
in their ecological traits. For example, Dark-eyed Juncos were found on roughly three times as many survey blocks in the early vs. late era, and saw their urban index shift from strongly negative in the early era $(-0.56)$ to weakly negative by the late era $(-0.15)$ (Supplementary Table S1). This species is now a yearround resident across the Los Angeles Basin, and is frequently found nesting in structures, including within parking structures in urban Los Angeles (D.S. Cooper pers. obs.); decades ago it was largely a migratory ground-nester, restricted to montane areas for breeding (Garrett and Dunn, 1981; Allen et al., 2016). Likewise, structure-nesting in Cassin's Kingbirds was not mentioned in recent breeding bird atlases based on data from the 1990s (Unitt, 2004; Allen et al., 2016), but this tendency has since become a frequent sight around Los Angeles (pers. obs.), during which time this species has increased its representation on survey blocks roughly fourfold. We encourage more research on the differential usage of cavities and artificial structures in urban areas and at the urban edge, as urban-colonizing species continue to utilize new substrates for breeding (see Reynolds et al., 2019).

Our finding that overall, species were found more widely (i.e., in more survey blocks) and with higher urban indices in the late era than the early one may be an artifact of the two different methodologies used in data collection rather than a biological pattern. This is likely a result of the more inclusive approach assigning breeding status from the (later) eBird data (where only breeding season records of single birds or pairs was used to denote breeding) versus the more conservative approach used in generating the BBA data, which required observers to justify their assessment of nesting with field observations. Thus, birds recorded only once in 5 years in a given block might not have warranted a "possibly breeding" (i.e., code 1) assignment in the early era, because these determinations were often made post hoc and somewhat subjectively by the atlas coordinators, based on suitable habitat, other nesting behavior, etc. (see Allen et al., 2016); yet for the late era dataset, a “one-off” sighting would have been counted as possibly breeding. Because reliable abundance data were not available for the Breeding Bird Atlas, we did not calculate abundance using the eBird data, and simply used scores between 0 and 2, summing them as a substitute for abundance across all 173 blocks. Abundance should be more easily calculated in the future as community-science projects expand and the amount of point data increases, allowing for more granular studies into local and regional biodiversity, population and range shifts, and community organization (e.g., Ballard et al., 2017; Callaghan et al., 2017; Jarić et al., 2020). Although we limited our analysis to the breeding season, when our focal bird species would likely be tied to a specific territory and thus dependent on the local resources available for themselves and their offspring (Mills et al., 1989), a similar analysis could be performed for wintering or even transient species using data collected at other times of year, a period when urban habitats are utilized by a diversity of native bird species (e.g., Wood and Esaian, 2020).

Finally, as urbanization continues to expand globally, we encourage further reflection on ways to define "success" in urban areas. On one hand, cities may be considered successful if they include built features that can support a high diversity of species, some of which would not have occurred prior to urbanization
(White et al., 2005; Filazzola et al., 2019). Yet cities must also allow the least-adaptable species - those most strongly associated with wildland rather than urban habitats - to find refuge within the urban matrix as they urbanize (Sol et al., 2014). Much of this tension results from studies using different scales of analysis; high local diversity may be easier to achieve within cities than high global diversity, which requires the conservation of rare and endemic species (e.g., Enedino et al., 2018; McDonald et al., 2018). Place matters, too, and while a featureless desert may support relatively few bird species compared to the oasis-like city that replaces it (e.g., Gonzalez-Garcia et al., 2014), this scenario would hardly be considered a desirable conservation to be replicated everywhere (otherwise, why not cover the earth in cities?). Thus, an understanding of the mechanics of urban bird community development is merely a necessary first step on the way to developing meaningful conservation goals.

\section{DATA AVAILABILITY STATEMENT}

All datasets generated for this study are included in the article/Supplementary Material.

\section{AUTHOR CONTRIBUTIONS}

DC and AS: conceptualization, methodology, and data analysis. DB: methodology and supervision. DC: Writing, including original draft. All authors: review and editing.

\section{ACKNOWLEDGMENTS}

We thank the Sustainable L.A. Grand Challenge for providing financial support for graduate work of DC (especially M. Gold and C. Rausser). We thank K. Garrett at the Natural History Museum, Los Angeles County for providing atlas data, including unpublished data tables and field notes, and for insight into the interpretation of these data. We also thank the numerous contributors to eBird within Los Angeles County, including the observers, data reviewers, and the project team at the Cornell Lab of Ornithology. Museum staff G. Pauly, J. Vendetti, and members of the Urban Nature Research Center provided helpful comments on an early draft of the manuscript. R. Harrigan assisted with statistical analysis, and M. Dimson, T. Zagelbaum, and S. Contreras assisted with geo-spatial analysis.

\section{SUPPLEMENTARY MATERIAL}

The Supplementary Material for this article can be found online at: https://www.frontiersin.org/articles/10.3389/fevo.2020.00251/ full\#supplementary-material 


\section{REFERENCES}

Aldrich, J. W., and Coffin, R. W. (1980). Breeding bird populations from forest to suburbia after thirty-seven years. Am. Birds 34, 3-7.

Allen, L., Garrett, K. L., and Wimer, M. (2016). Los Angeles County Breeding Bird Atlas. Los Angeles, CA: Los Angeles Audubon Society.

Allen, L. W., and Garrett, K. L. (1995). Atlas Handbook: Los Angeles County Breeding Bird Atlas. Los Angeles, CA: Los Angeles Audubon Society.

Atwell, J. W., Cardoso, G. C., Whittaker, D. J., Campbell-Nelson, S., Robertson, K. W., and Ketterson, E. D. (2012). Boldness behavior and stress physiology in a novel urban environment suggest rapid correlated evolutionary adaptation. Behav. Ecol. 23, 960-969. doi: 10.1093/beheco/ars059

Ballard, H. B., Robinson, L. D., Young, A. N., Pauly, G. B., Higgins, L. M., Johnson, R. F., et al. (2017). Contributions to conservation outcomes of natural history museum-led citizen science: examining evidence and next steps. Biol. Cons. 208, 87-97. doi: 10.1016/j.biocon.2016.08.040

Beissinger, S. R., and Osborne, D. R. (1982). Effects of urbanization on avian community organization. Condor $84,75-83$.

Beninde, J., Veith, M., and Hochkirch, A. (2015). Biodiversity in cities needs space: a meta-analysis of factors determining intra-urban biodiversity variation. Ecol. Lett. 18, 581-592. doi: 10.1111/ele.12427

Blair, R. B. (1996). Land use and avian species diversity along an urban gradient. Ecol. Appl. 6, 506-519. doi: 10.2307/2269387

Blewett, C. M., and Marzluff, J. M. (2005). Effects of urban sprawl on snags and the abundance and productivity of cavity-nesting birds. Condor 107, 678-693. doi: 10.1093/condor/107.3.678

Blomberg, S. P., Garland, T., and Ives, A. R. (2003). Testing for phylogenetic signal in comparative data: behavioral traits are more labile. Evolution 57, 717-745. doi: 10.1111/j.0014-3820.2003.tb00285.x

Blumstein, D. T. (2006). Developing an evolutionary ecology of fear: how life history and natural history traits affect disturbance tolerance in birds. Anim. Behav. 71, 389-399. doi: 10.1016/j.anbehav.2005.05.010

Blumstein, D. T. (2014). "Attention, habituation, and antipredator behavior: implications for birds," in Avian Urban Ecology, eds D. Gil, and H. Brumm (Oxford: Oxford Univ. Press), 41-53. doi: 10.1093/acprof:osobl/ 9780199661572.003.0004

Boal, C. W., and Mannan, R. W. (1999). Comparative breeding ecology of Cooper's hawks in urban and exurban areas of southeastern Arizona. J. Wildl. Manag. 63, 77-84.

Bonier, F., Martin, P. R., and Wingfield, J. C. (2007). Urban birds have broader environmental tolerance. Biol. Lett. 3, 670-673. doi: 10.1098/rsbl.2007.0349

Callaghan, C. T., Lyons, M. B., Martin, J. M., Major, R. E., and Kingsford, R. T. (2017). Assessing the reliability of avian biodiversity measures of urban greenspaces using eBird citizen science data. Avian Cons. Ecol. 12:12.

CALVEG, (2009). South Coast and Montane Ecological Province, CALVEG Zone 7. Available at: https://www.fs.usda.gov/detail/r5/landmanagement/ resourcemanagement/?cid=stelprdb5347192 (accessed August 10, 2018).

Carrete, M., and Tella, J. L. (2011). Inter-Individual variability in fear of humans and relative brain size of the species are related to contemporary urban invasion in birds. PLoS One 6:e18859. doi: 10.1371/journal.pone.0018859

Center for Geographical Studies (2015). A Shared Vision for The Survey of California Vegetation. Los Angeles, CA: California State University.

Chace, J. F., and Walsh, J. J. (2006). Urban effects on native avifauna: a review. Landsc. Urb. Plan. 74, 46-69. doi: 10.1016/j.landurbplan.2004.08.007

City of Los Angeles (2018). 2018 Biodiversity report: Measurement of the Singapore Index of Cities' Biodiversity and Recommendations for a Customized Los Angeles Index. Available at: https://www.lacitysan.org/cs/groups/public/ documents/document/y250/mdi0/ \{\}edisp/cnt024743.pdf (accessed July 2, 2020).

Clergeau, P., Jokimäki, J., and Savard, J.-P. (2001). Are urban bird communities influenced by the bird diversity of adjacent landscapes. J. Appl. Ecol. 28, 1122-1134. doi: 10.1046/j.1365-2664.2001.00666.x

Croci, S., Butet, A., and Clergeau, P. (2008). Does urbanization filter birds on the basis of their biological traits? Condor 110, 223-240. doi: 10.1525/cond.2008. 8409

Devictor, V., Julliard, R., Couvet, D., Lee, A., and Jiguet, F. (2007). Functional homogenization effect of urbanization on bird communities. Cons. Biol. 21, 741-751. doi: 10.1111/j.1523-1739.2007.00671.x
Diamond, J. M., and Ross, M. S. (2019). Exotic parrots breeding in urban tree cavities: nesting requirements, geographic distribution, and potential impacts on cavity nesting birds in southeast Florida. Avian Res. 10:39.

Dunning, J. B. (2007). CRC Handbook of Avian Body Masses, 2nd Edn. Boca Raton, FL: CRC Press.

Ehrlich, P. R., Dobkin, D. S., and Wheye, D. (1988). The Birder's Handbook: A Field Guide to the Natural History of North American Birds. New York: Simon and Schuster/Fireside Books.

Emlen, J. T. (1974). An urban bird community in Tucson, Arizona: derivation, structure, regulation. Condor 76, 184-197.

Enedino, T. R., Loures-Ribeiro, A., and Santos, B. A. (2018). Protecting biodiversity in urbanizing regions: the role of urban reserves for the conservation of Brazilian Atlantic Forest birds. Perspect. Ecol. Const. 16, 17-23. doi: 10.1016/ j.pecon.2017.11.001

Estes, W. A., and Mannan, R. W. (2003). Feeding behavior of Cooper's Hawks at urban and rural nests in southeastern Arizona. Condor 105, 107-116. doi: 10.1093/condor/105.1.107

Evans, J., Boudreau, K., and Hyman, J. (2010). Behavioral syndromes in urban and rural populations of song sparrows. Ethology 116, 588-595.

Evans, K. L., Chamberlain, D. E., Hatchwell, B. J., Gregory, R. D., and Gaston, K. J. (2011). What makes an urban bird? Glob. Change Biol. 17, 32-44. doi: 10.1111/j.1365-2486.2010.02247.x

Ferenc, M., Sedláeek, O., Fuchs, R., Dinetti, M., Fraissinet, M., and Storch, D. (2014). Are cities different? Patterns of species richness and beta diversity of urban bird communities and regional species assemblages in Europe. Glob. Ecol. Biogeogr. 23, 479-489. doi: 10.1111/geb.12130

Filazzola, A., Shrestha, N., and MacIvor, J. S. (2019). The contribution of constructed green infrastructure to urban biodiversity: a synthesis and metaanalysis. J. Appl. Ecol. 56, 2131-2143.

Francis, C. D., Ortega, C. P., and Cruz, A. (2009). Noise pollution changes avian communities and species interactions. Curr. Biol. 19, 1415-1419. doi: 10.1016/ j.cub.2009.06.052

Frank, S. D., Backe, K. M., McDaniel, C., Green, M., Widney, S., and Dunn, R. R. (2019). Exotic urban trees conserve similar natural enemy communities to native congeners but have fewer pests. PeerJ 7:e6531. doi: 10.7717/peerj.6531

Garrett, K., and Dunn, J. (1981). Birds of Southern California: Status and Distribution. Los Angeles, CA: Los Angeles Audubon Society.

Garrett, K. L. (2018). "Introducing change: a current look at naturalized bird species in western North America in Trends and traditions: avifaunal change in western North America," in Studies of Western Birds 3, eds W. D. Shuford, R. E. Gill, Jr., and C. M. Handel, (Camarillo, CA: Western Field Ornithologists), 116-130. doi: 10.21199/swb3.5

Gillespie, T. W., Pincetl, S., Brossard, S., Smith, J., Saatchi, S., Pataki, D., et al. (2011). A time series of urban forestry in Los Angeles. Urb. Ecosyst. 15, 233-246. doi: 10.1007/s11252-011-0183-6

Gonzalez-Garcia, F., Straub, R., Lobato Garcia, J. A., and MacGregor-Fors, I. (2014). Birds of a neotropical green city: an up-to-date review of the avifauna of the city of Xalapa with additional unpublished records. Urb. Ecosyst. 17, 991-1012. doi: 10.1007/s11252-014-0370-3

Grinnell, J. (1898). Birds of the Pacific slope of Los Angeles County. Pasadena, NL: Pasadena Academy of Sciences.

Gutzat, F., and Dormann, C. (2018). Decaying trees improve nesting opportunities for cavity-nesting birds in temperate and boreal forests: a meta-analysis and implications for retention forestry. Ecol. Evol. 8, 8616-8626. doi: 10.1002/ece3. 4245

Hackett, S. J., Kimball, R. T., Reddy, S., Bowie, R. C. K., Braun, E. L., Braun, M. J., et al. (2008). A phylogenomic study of birds reveals their evolutionary history. Science 320, 1763-1768.

Hagen, E. O., Hagen, O., Ibáñez-Álamo, J. D., Petchey, O. L., and Evans, K. L. (2017). Impacts of urban areas and their characteristics on avian functional diversity. Front. Ecol. Evol. 5:84. doi: 10.3389/fevo.2017.00084

Harrell, F. E. (2004). Hmisc S Function Library. Available at: http://biostat.mc. vanderbilt.edu/s/Hmisc (accessed October 22, 2019).

Higgins, L., Pauly, G. B., Goldman, J. G., and Hood, C. (2019). Wild LA. Portland: Timber Press.

Horns, J. J., Alder, F. R., and Sekercioglu, C. H. (2018). Using opportunistic citizen science data to estimate average population trends. Biol. Constr. 221, 151-159. doi: 10.1016/j.biocon.2018.02.027 
Iacus, S. M. (2016). sde: Simulation and Inference for Stochastic Differential Equations. R package version 2.0.15.

Jarić, I., Correia, R. A., Brook, B. W., Buettel, J. C., and Roll, U. (2020). iEcology: harnessing large online resources to generate ecological insights. TREE 35, 630-639. doi: 10.1016/j.tree.2020.03.003

Jetz, W., Thomas, G. H., Joy, J. B., Hartmann, K., and Mooers, A. O. (2012). The global diversity of birds in space and time. Nature 491, 444-448. doi: 10.1038/nature11631

Jetz, W., Thomas, G. H., Joy, J. B., Hartmann, K., Redding, D., and Mooers, A. O. (2014). Distribution and conservation of global evolutionary distinctness in birds. Curr. Biol. 24, 919-930. doi: 10.1016/j.cub.2014.03.011

Johnston, R. F. (2001). "Synanthropic birds of North America," in Avian Ecology and Conservation in an Urbanizing World, eds J. M. Marzluff, R. Bowman, and R. Donnelly, (Boston, MA: Springer), 49-67. doi: 10.1007/978-1-4615-153 $1-9 \_3$

Jokimäki, J., Suhonen, J., Vuorisalo, T., Kover, L., and Kaisanlahti-Jokimäki, J. (2017). Urbanization and nest-site selection of the black-billed magpie (Pica pica) populations in two Finnish cities: from a persecuted species to an urban exploiter. Landsc. Urb. Plan. 157, 577-585. doi: 10.1016/j.landurbplan.2016.0 8.001

Kark, S., Iwaniuk, A., Schalimtzek, A., and Banker, E. (2007). Living in the city: can anyone become an 'urban exploiter'? J. Biogeogr. 34, 638-651. doi: 10.1111/j. 1365-2699.2006.01638.x

Kembel, S. W., Cowan, P. D., Helmus, M. R., Cornwell, W. K., Morlon, H., Ackerly, S. P., et al. (2010). Picante: R tools for integrating phylogenies and ecology. Bioinformatics 26, 1463-1464. doi: 10.1093/bioinformatics/btq166

Kettel, E. F., Gentle, L. K., Quinn, J. L., and Yarnell, R. W. (2018). The breeding performance of raptors in urban landscapes: a review and meta-analysis. J. Ornithol. 159, 1-18. doi: 10.1007/s10336-017-1497-9

Koch, A. J., Martin, K., and Aitken, K. E. H. (2012). The relationship between introduced European Starlings and the reproductive activities of Mountain Bluebirds and Tree Swallows in British Columbia, Canada. IBIS 154, 590-600. doi: 10.1111/j.1474-919x.2012.01242.x

Lee, S. J., Longcore, T. L., Rich, C., and Wilson, J. P. (2017). Increased home size and hardscape decreases urban forest cover in Los Angeles County's singlefamily residential neighborhoods. Urb. Forestry Urb. Greening 24, 222-235. doi: 10.1016/j.ufug.2017.03.004

Li, E., Parker, S. S., Pauly, G. B., Randall, J. M., Brown, B. V., and Cohen, B. S. (2019). An urban biodiversity assessment framework that combines an urban habitat classification scheme and citizen science data. Front. Ecol. Evol. 7:277. doi: $10.3389 /$ fevo.2019.00277

Los Angeles Almanac, (2019). Historical General Population, City \& County of Los Angeles, 1850 to 2010." Los Angeles Almanac. Copyright 1998-2019 Given Place Media, publishing as Los Angeles Almanac. Available at: http://www.laalmanac. com/population/po02.php (accessed 5 December 2019).

Loss, S. R., Will, T., and Marra, P. P. (2013). The impact of free ranging domestic cats on wildlife of the United States. Nat. Commun. 4:1396.

Lowry, H., Lill, A., and Wong, B. B. M. (2013). Behavioural responses of wildlife to urban environments. Biol. Rev. 88, 537-549. doi: 10.1111/brv.12012

MacGregor-Fors, I. (2010). How to measure the urban-wildland ecotones: Redefining 'peri-urban' areas. Ecol. Res. 25, 883-997.

MacGregor-Fors, I., and Ortega-Alvarez, R. (2011). Fading from the forest: bird community shifts related to urban site-specific and landscape traits. Urb. Forestry Urb. Greening 10, 239-246. doi: 10.1016/j.ufug.2011. 03.004

Martin, P. R., and Bonier, F. (2018). Species interactions limit the occurrence of urban-adapted birds in cities. PNAS 115, E11495-E11504.

Martins, E. P. (1994). Estimating the rate of phenotypic evolution from comparative data. Am. Nat. 144, 193-209. doi: 10.1086/285670

Marzluff, J. M. (2005). Island biogeography for an urbanizing world: how extinction and colonization may determine biological diversity in humandominated landscapes. Urb. Ecosyst. 8, 157-177. doi: 10.1007/s11252-0054378-6

Marzluff, J. M. (2016). A decadal review of urban ornithology and prospectus for the future. IBIS 159, 1-13. doi: 10.1111/ibi.12430

Marzluff, J. M., Bowman, R., and Donnely, R. (2001). "A historical perspective on urban bird research: trends, terms, and approaches," in Avian Conservation and Ecology in an Urbanizing World, eds J. M. Marzluff, R. Bowman, and R.
Donnely, (Boston, MA: Kluwer Academic), 1-17. doi: 10.1007/978-1-46151531-9_1

Marzluff, J. M., Clucas, B., Oleyar, M. D., and DeLap, J. (2015). The causal response of avian communities to suburban development: a quasi-experimental, longitudinal study. Urb. Ecosyst. 19, 1597-1621. doi: 10.1007/s11252-0150483-3

McDonald, R. I., Güneralp, B., Huang, C.-W., Seto, K. C., and You, M. (2018). Conservation priorities to protect certebrate endemics from global urban expansion. Biol. Constr. 224, 290-299. doi: 10.1016/j.biocon.2018.06.010

McKinney, M. L. (2006). Urbanization as a major cause of biotic homogenization. Biol. Constr. 127, 247-260. doi: 10.1016/j.biocon.2005.09.005

Merckx, T., Souffreau, C., Kaiser, A., Baardsen, L. F., Backeljau, T., Bonte, D., et al. (2018). Body-size shifts in aquatic and terrestrial urban communities. Nature $558,113-116$.

Mills, G. S., Dunning, J. B. Jr., and Bates, J. M. (1989). Effects of urbanization on breeding bird community structure in southwestern desert habitats. Condor 91, $416-428$.

Møller, A. P. (2009). Successful city dwellers: a comparative study of the ecological characteristics of urban birds in the Western Palearctic. Oecologia 159, 849-858. doi: 10.1007/s00442-008-1259-8

Møller, A. P. (2010). Interspecific variation in fear responses predicts urbanization in birds. Behav. Ecol. 21, 365-371. doi: 10.1093/beheco/arp199

Møller, A. P. (2014). "Behavioral and ecological predictors of urbanization," in Avian Urban Ecology, eds D. Gil, and H. Brumm, (Oxford: Oxford Univ. Press), 54-68. doi: 10.1093/acprof:osobl/9780199661572.003.0005

Møller, A. P., Diaz, M., Flensted-Jensen, E., Grim, T., Ibanez-Alamo, J. D., Jokimäki, J., et al. (2015). Urbanized birds have superior establishment success in novel environments. Oecologia 178, 943-950. doi: 10.1007/s00442-0153268-8

Münkemüller, T., Lavergne, S., Bzeznik, B., Dray, S., Jombart, T., Schiffers, K., et al. (2012). How to measure and test phylogenetic signal. Method Ecol. Evol. 3, 743-756. doi: 10.1111/j.2041-210x.2012.00196.x

O'Leary, R., and Jones, D. N. (2006). The use of supplementary foods by Australian magpies Gymnorhina tibicen: implications for wildlife feeding in suburban environments. Austral. Ecol. 31, 208-216. doi: 10.1111/j.1442-9993.2006. 01583.x

Pagel, M. D. (1999). Inferring the historical patterns of biological evolution. Nature 401, 877-884. doi: $10.1038 / 44766$

Paradis, E., Claude, J., and Strimmer, K. (2004). APE: analyses of phylogenetics and evolution in R language. Bioinformatics 20, 289-290. doi: 10.1093/ bioinformatics/btg 412

Pauli, B. P., Spaul, R. J., and Heath, J. A. (2016). Forecasting disturbance effects on wildlife: tolerance does not mitigate effects of increased recreation on wildlands. Anim. Constr. 20, 251-260. doi: 10.1111/acv.12308

Pennell, M. W., Eastman, J. M., Slater, G. J., Brown, J. W., Uyeda, J. C., FitzJohn, R. G., et al. (2014). geiger v2.0: an expanded suite of methods for fitting macroevolutionary models to phylogenetic trees. Bioinformatics 30, 2216-2218. doi: 10.1093/bioinformatics/btu181

Pinheiro, J., Bates, D., DebRoy, S., Sarkar, D., and R Core Team, (2019). nlme: Linear and Nonlinear Mixed Effects Models. R Pack. Vers. 3.1-143.

QGIS Development Team, (2016). QGIS Geographic Information System. Open Source Geospatial Foundation Project. Available at: http://qgis.osgeo.org (accessed September 4, 2019).

Revell, L. J. (2012). Phytools: an R package for phylogenetic comparative biology (and other things). Method Ecol. Evol. 3, 217-223. doi: 10.1111/j.2041-210x. 2011.00169.x

Reynolds, S. J., Ibáñez-Álamo, J. D., Sumasgutner, P., and Mainwaring, M. C. (2019). Urbanisation and nest building in birds: a review of threats and opportunities. J. Ornith. 160, 841-860. doi: 10.1007/s10336-019-01657-8

Samia, D. S. M., Nakagawa, S., Nomura, F., Rangel, T. F., and Blumstein, D. T. (2015). Increased tolerance to humans among disturbed wildlife. Nat. Commun. 6:8877.

Santini, L., González-Suárez, M., Russo, D., Gonzalez-Voyer, A., Von Hardenberg, A., and Ancillotto, L. (2019). One strategy does not fit all: determinants of urban adaptation in mammals. Ecol. Lett. 22, 365-376. doi: 10.1111/ele. 13199

Santos, M. J., Smith, A. B., Thorne, J. H., and Moritz, C. (2017). The relative influence of change in habitat and climate on elevational range limits in small 
mammals in Yosemite National Park, California, U.S.A. Clim. Change Responses 4:7.

Schoenherr, A. A. (1992). A Natural History of California. California Natural History Guides: 56. Berkeley, CA: Univ. of California Press.

Shultz, A. J., Tingley, M. W., and Bowie, R. C. K. (2012). A century of avian community turnover in an urban green space in northern California. Condor 114, 258-267. doi: 10.1525/cond.2012.110029

Silva, C. P., García, C. E., Estay, S. A., and Barbosa, O. (2015). Bird richness and abundance in response to urban form in a Latin American city: valdivia, Chile as a case study. PLoS One 10:e0138120. doi: 10.1371/journal.pone.0138120

Slabbekoorn, H., and den Boer-Visser, A. (2006). Cities change the songs of birds. Curr. Biol. 16, 2326-2331. doi: 10.1016/j.cub.2006.10.008

Sol, D., Gonzalez-Lagos, C., Lapiedra, O., and Diaz, M. (2017). "Why are exotic birds so successful in urbanized environments?," in Ecology and Conservation of Birds in Urban Environments, eds E. Murgui, and M. Hedblom, (Boston, MA: Springer), 75-89. doi: 10.1007/978-3-319-43 314-1_5

Sol, D., González-Lagos, C., Moreira, D., Maspons, J., and Lapiedra, O. (2014). Urbanisation tolerance and the loss of avian diversity. Ecol. Lett. 17, 942-950. doi: 10.1111/ele.12297

Sol, D., Lapiedra, O., and González-Lagos, C. (2013). Behavioural adjustments for a life in the city. Anim. Behav. 85, 1101-1112. doi: 10.1016/j.anbehav.2013.01.023

Stein, E. D., Dark, S., Longcore, T., Hall, N., Beland, M., Grossinger, R., et al. (2007). Historical Ecology and Landscape Change of the San Gabriel River and Floodplain. Costa Mesa, CA: Southern California Coastal Water Research Project.

Swarth, H. S. (1900). Avifauna of a 100-acre ranch. Condor 2, 14-16. doi: 10.2307/ 1361152

Tomasevic, J. A., and Marzluff, J. M. (2017). Cavity nesting birds along an urban-wildland gradient: is human facilitation structuring in the bird community? Urb. Ecosyst. 20, 435-448. doi: 10.1007/s11252-0160605-6

Unitt, P. (2004). San Diego County Bird Atlas. El Cajon, CA: Sunbelt Publications.
Vitousek, P. M., Mooney, H. A., Lubchenco, J., and Melillo, J. M. (1997). Human domination of Earth's ecosystems. Science 277, 494-499. doi: 10.1126/science. 277.5325.494

West-Eberhard, M. J. (1989). Phenotypic plasticity and the origins of diversity. Ann. Rev. Ecol. Syst. 20, 249-278.

White, J. G., Antos, M. J., Fitzsimons, J. A., and Palmer, G. C. (2005). Nonuniform bird assemblages in urban environments: the influence of streetscape vegetation. Landsc. Urb. Plan. 71, 123-135. doi: 10.1016/j.landurbplan.2004. 02.006

Wilman, H., Belmaker, J., Simpson, J., de la Rosa, C., Rivadeneira, M. M., and Jetz, W. (2014). EltonTraits 1.0: species-level foraging attributes of the world's birds and mammals. Ecology 95:2027. doi: 10.1890/13-1 917.1

Wingfield, J. C., Krause, J. S., Perez, J. H., Chmura, H. E., Németh, Z., Word, K. R., et al. (2015). A mechanistic approach to understanding range shifts in a changing world: what makes a pioneer? Gen. Comp. Endocrinol. 222, 44-53. doi: 10.1016/j.ygcen.2015.08.022

Wood, E. M., and Esaian, S. (2020). The importance of street trees to urban avifauna. Ecol. Applic. (accessed July 19, 2020).

Yeh, P. J. (2004). Rapid evolution of a sexually selected trait following population establishment in a novel habitat. Evolution 58, 166-174. doi: 10.1111/j.00143820.2004.tb01583.x

Conflict of Interest: The authors declare that the research was conducted in the absence of any commercial or financial relationships that could be construed as a potential conflict of interest.

Copyright (c) 2020 Cooper, Shultz and Blumstein. This is an open-access article distributed under the terms of the Creative Commons Attribution License (CC BY). The use, distribution or reproduction in other forums is permitted, provided the original author(s) and the copyright owner(s) are credited and that the original publication in this journal is cited, in accordance with accepted academic practice. No use, distribution or reproduction is permitted which does not comply with these terms. 